\title{
Heartbeat: the role of antiplatelet therapy in treatment of COVID-19 infections
}

There are few effective therapies to reduce complications due to COVID-19 infection. Santoro and colleagues ${ }^{1}$ hypothesised that antiplatelet therapy (APT) might be beneficial given the 'high prevalence of platelet-fibrin-rich microthrombi in several organs' at autopsy. In a multicentre international registry of 7824 consecutive patients hospitalised with COVID-19 infection, 9\% received either single or dual APT. Compared with those with no APT, univariate analysis showed that patients treated with an APT had a shorter duration of mechanical ventilation $(8 \pm 5$ days vs $11 \pm 7$ days, $p=0.01$ ) but no difference in hospital mortality, need for invasive ventilation, embolic events or bleeding. However, on multivariable analysis with consideration of baseline clinical factors, treatment with APT during hospitalisation for COVID-19 was associated with a lower mortality risk (relative risk $0.39,95 \% \mathrm{CI} 0.32$ to $0.48, \mathrm{p}<0.01$ ) (table 1).

Voruganti and colleagues ${ }^{2}$ put this data in context, including a table summarising previous publications that reported outcomes in patients with COVID-19 on APT. They conclude 'The study by Santoro et $a l^{1}$ is a step in the right direction to improve the outcomes of patients with COVID19. The use of an antiplatelet agent, mainly aspirin, might improve clinical outcomes without increasing the risk of side effects such as bleeding'. However, this potential benefit must be weighed against the risk of bleeding in each patient and further research is needed to determine the optimal APT agent. In my view, these findings should be evaluated in an RCT before making firm clinical recommendations.

The association between premature ventricular contraction (PVC) frequency and incident heart failure has not been studied previously in a community-based setting. In this issue

Division of Cardiology, University of Washington, Seattle, Washington, USA

Correspondence to Professor Catherine M Otto, Division of Cardiology, University of Washington, Seattle,WA 98195, USA; cmotto@uw.edu

\begin{tabular}{|c|c|c|c|c|}
\hline & Risk ratio & $\begin{array}{l}\text { Risk ratio } \\
95 \% \text { lower }\end{array}$ & $\begin{array}{l}\text { Risk ratio } \\
95 \% \text { upper }\end{array}$ & $P$ value \\
\hline Male & 1.20 & 1.08 & 1.34 & 0.0009 \\
\hline Age & 1.05 & 1.04 & 1.05 & $<0.0001$ \\
\hline Hypertension & 1.10 & 0.98 & 1.24 & 0.1150 \\
\hline Diabetes & 1.13 & 1.01 & 1.27 & 0.0363 \\
\hline History of cancer & 1.22 & 1.07 & 1.38 & 0.0026 \\
\hline Renal failure & 1.48 & 1.27 & 1.71 & $<0.0001$ \\
\hline Respiratory failure & 6.10 & 5.08 & 7.32 & $<0.0001$ \\
\hline Heart failure & 1.24 & 1.08 & 1.43 & 0.0021 \\
\hline Invasive ventilation & 2.08 & 1.82 & 2.37 & $<0.0001$ \\
\hline Prior antiplatelet therapy & 1.53 & 1.37 & 1.71 & $<0.0001$ \\
\hline In-hospital anticoagulant therapy & 0.99 & 0.99 & 0.99 & $<0.0001$ \\
\hline In-hospital antiplatelet therapy & 0.39 & 0.32 & 0.48 & $<0.0001$ \\
\hline
\end{tabular}

of Heart, Limpitikul and colleagues ${ }^{3}$ examined 24-hour ambulatory ECG monitoring in 871 participants in the population-based cardiovascular health study; $36 \%$ had a 10 or more PVCs per 24 hours and 34\% developed heart failure (HF) over a median of 11 years

follow-up. After correcting for baseline characteristics, greater heterogeneity in the PCV coupling interval (but not the interval itself) was associated with a higher risk of decline in left ventricular systolic function and incident $\mathrm{HF}$ (figure 1).

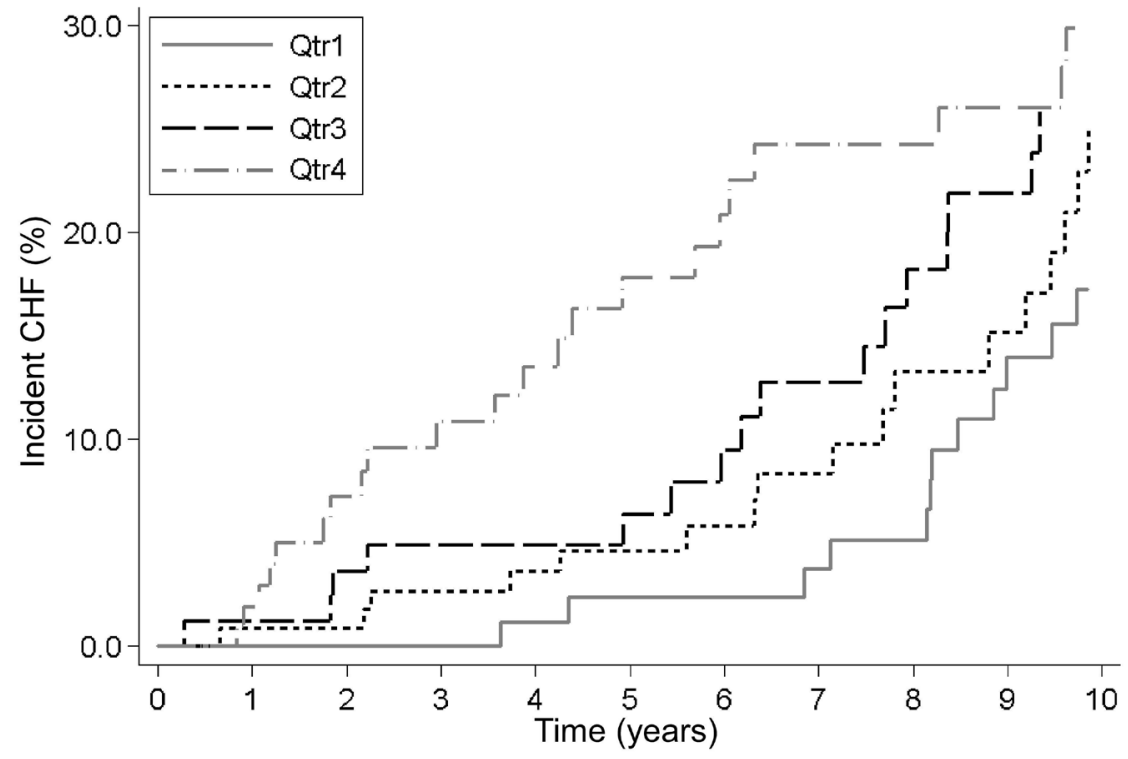

Figure 1 Association between quartiles of coupling interval heterogeneity and incident CHF over time. Kaplan-Meier curves adjusted for age, gender, race, body mass index, history of diabetes, hypertension, myocardial infarction, smoking, use of Vaughan-Williams class la, Ib, Ic, II and IV antiarrhythmics, PVC frequency, PVC duration and coupling interval duration. CHF, congestive heart failure; PVC, premature ventricular complex. 


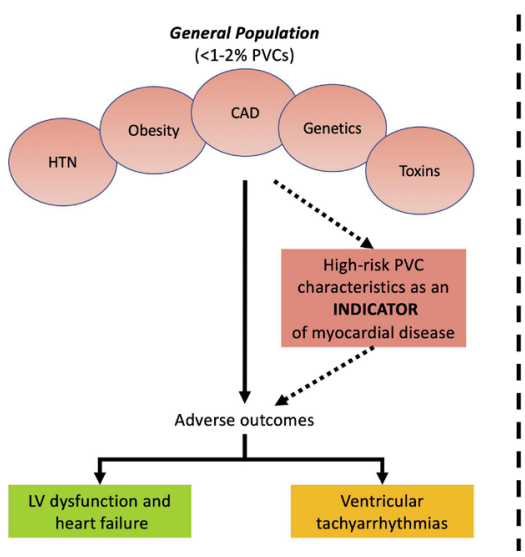

Figure 2 Conceptualisation of the relationship between PVCs and outcomes. CAD, coronary artery disease; HTN, hypertension; LV, left ventricle/ventricular; PVC, premature ventricular complex.
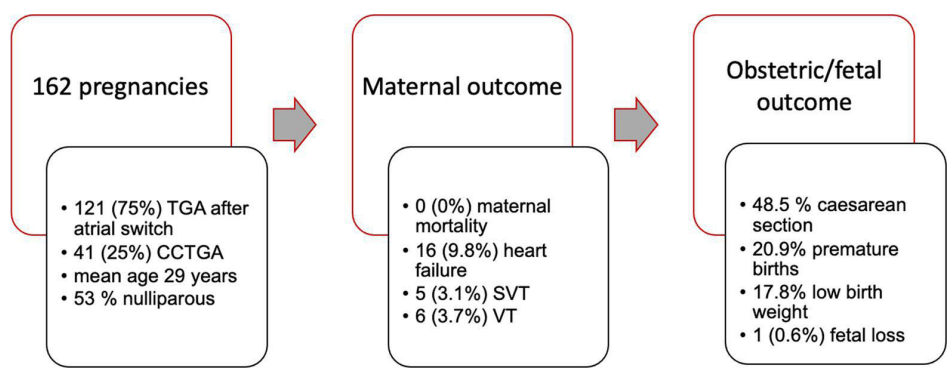

Figure 3 Maternal and fetal outcome. CCTGA, congenitally corrected transposition of the great arteries; SVT, supraventricular tachycardia; VT, ventricular tachycardia.

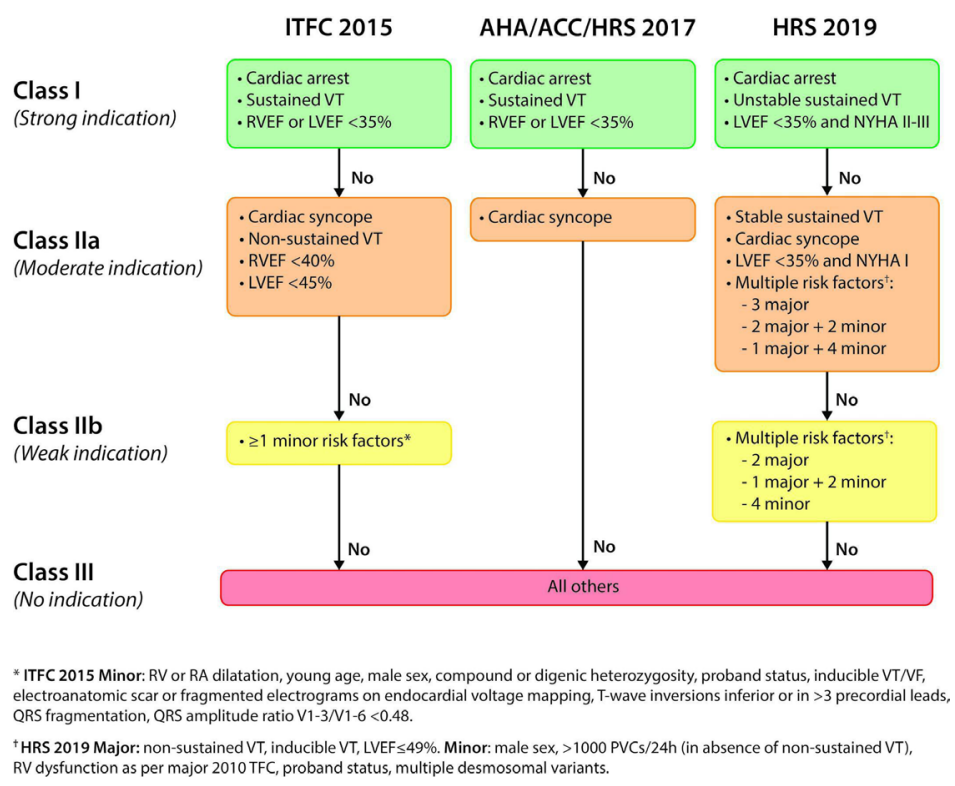

Figure 4 Expert statement/guideline ICD indication algorithms. overview of the three flow diagram algorithms for implantable cardioverter-defibrillator (ICD) indication, from the 2015 ARVC International Task Force Consensus (ITFC 2015), ${ }^{8}$ the 2017 American Heart Association/ American College of Cardiology/Heart Rhythm Society ventricular arrhythmia guideline (AHA/ ACC/HRS 2017) ${ }^{9}$ and the 2019 Arrhythmogenic Cardiomyopathy Heart Rhythm Society Consensus (HRS 2019). ${ }^{10}$ ARVC, arrhythmogenic right ventricular cardiomyopathy; NYHA, New York Heart Association; LVEF, left ventricular ejection fraction; PVC, premature ventricular complex; RA, right atrium; RVEF, right ventricular ejection fraction; VF, ventricular fibrillation; VT, ventricular tachycardia.
In the accompanying editorial, Deyell and Hawkins ${ }^{4}$ discuss the complex interplay between PVCs and HF including(1) PVCs as a manifestation of underlying myocardial disease, (2) a high PVC burden causing HF which may resolve after PVC ablation, and (3) PVC coupling heterogenicity in healthy adults indicating a higher risk of incident $\mathrm{HF}$ as shown in the study by Limpitikul and colleagues (figure 2). ${ }^{3}$ They go on to point out the heterogeneity in PVC coupling intervals is primarily determined by the underlying arrhythmic mechanism. 'Fixed and low coupling interval variation is more indicative of re-entrant or triggered mechanisms for PVCs, that are associated with a higher risk of sudden death in structural heart disease. Conversely, high variability is more indicative of automaticity, and more specifically modulated parasystole, as the mechanism'. 'Consequently, high variability in coupling interval is more predictive of $\mathrm{HF}$ rather than ventricular tachyarrhythmias'.

In another interesting paper in this issue of Heart, Tutarel and colleagues ${ }^{5}$ show that the majority of pregnant women with a systemic right ventricle due to congenital heart disease, tolerate pregnancy well with favourable fetal outcomes, based on data from a multicentre registry (figure 3).

Clinicians will find a concise update on arrhythmogenic right ventricular dysplasia in a review article by Bosman and Te Reile ${ }^{6}$ including a flow chart with the indications proposed by different societies for an implantable cardioverter defibrillator in paitents with this condition (figure 4).

The Education in Heart article in this issue, ${ }^{7}$ summarises the contemporary management of persistent atrial fibrillation (AF). Treatment focuses on risk factor modification, stroke prevention, rhythm control and rate control. Catheter ablation of AF reduces symptoms and improves quality of life in most patients and has the potential for survival benefit in those with coexisting HF. The 'pace and ablate' strategy is palliative and reserved for patients in whom catheter ablation is not appropriate or unsuccessful and are refractory to pharmacological rate control therapy.

Contributors Heartbeat 108 Issue 2.

Funding The authors have not declared a specific grant for this research from any funding agency in the public, commercial or not-for-profit sectors.

Competing interests None declared. 
Patient and public involvement Patients and/or the public were not involved in the design, or conduct, or reporting, or dissemination plans of this research.

Patient consent for publication Not applicable.

Ethics approval This study does not involve human participants.

Provenance and peer review Commissioned; internally peer reviewed.

This article is made freely available for use in accordance with BMJ's website terms and conditions for the duration of the covid-19 pandemic or until otherwise determined by BMJ. You may use, download and print the article for any lawful, non-commercial purpose (including text and data mining) provided that all copyright notices and trade marks are retained.

(C) Author(s) (or their employer(s)) 2022. No commercial re-use. See rights and permissions. Published by BMJ.

\section{D) Check for updates}

To cite Otto CM. Heart 2022;108:83-85.

Heart 2022;108:83-85

doi:10.1136/heartjnl-2021-320691

ORCID iD

Catherine M Otto http://orcid.org/0000-0002-05279392

\section{REFERENCES}

1 Santoro F, Nuñez-Gil IJ, Vitale E, et al. Antiplatelet therapy and outcome in COVID-19: the health outcome predictive evaluation registry. Heart 2022;108:130-6.

2 Voruganti D, Bassareo PP, Calcaterra G, et al. Does aspirin save lives in patients with COVID-19? Heart 2022:108:88-9.

3 Limpitikul WB, Dewland TA, Vittinghoff E, et al. Premature ventricular complexes and development of heart failure in a community-based population. Heart 2022:108:105-10.

4 Deyell MW, Hawkins NM. Odd couple: premature ventricular contractions and heart failure. Heart 2022;108:86-7.

5 Tutarel O, Baris L, Budts W, et al. Pregnancy outcomes in women with a systemic right ventricle and transposition of the great arteries results from the ESC-EORP registry of pregnancy and cardiac disease (ROPAC). Heart 2022;108:117-23.

6 Bosman LP, te Riele ASJM. Arrhythmogenic right ventricular cardiomyopathy: a focused update on diagnosis and risk stratification. Heart 2022;108:90-7.

7 Gupta D, Ding WY. Contemporary management of persistent atrial fibrillation. Heart 2022;108:145-51.

8 Corrado D, Wichter T, Link MS, et al. Treatment of arrhythmogenic right ventricular cardiomyopathy/ dysplasia. Circulation 2015;132:441-53.

9 Al-Khatib SM, Stevenson WG, Ackerman MJ, et al. 2017 AHA/ACC/HRS guideline for management of patients with ventricular arrhythmias and the prevention of sudden cardiac death: a report of the American College of Cardiology/American heart association Task force on clinical practice guidelines and the heart rhythm Society. J Am Coll Cardiol 2018;72:e91-220.

10 Towbin JA, McKenna WJ, Abrams DJ. HRS expert consensus statement on evaluation, risk stratification, and management of arrhythmogenic cardiomyopathy. Heart Rhythm 2019;2019:e301-72. 